\title{
PATTERN AND RISK FACTOR ASSOCIATED WITH CONGENITAL ANOMALIES AMONG YOUNG INFANTS ADMITTED IN DHULIKHEL HOSPITAL
}

\author{
Dongol $S^{1^{*}}$, Sradanandha $S^{2}$, Shrestha $S^{3}$, Shrestha RPB ${ }^{4}$, Poudyal $P^{5}$
}

\section{Affiliation}

1 Associate Professor, Department of Pediatrics Dhulikhel Hospital, Kathmandu University Hospital, Dhulikhel, Nepal.

2. Assistant Professor, Department of Community medicine, Dhulikhel Hospital, Kathmandu University Hospital, Dhulikhel, Nepal.

3. Lecturer, Department of Community medicine, Dhulikhel Hospital, Kathmandu University Hospital, Dhulikhel, Nepal.

4. Professor, Department of Pediatrics, Dhulikhel Hospital, Kathmandu University Hospital, Dhulikhel, Nepal.

5. Lecturer, Department of Pediatrics, Dhulikhel Hospital, Kathmandu University Hospital, Dhulikhel, Nepal.

\section{ARTICLE INFO}

\section{Article History}

Received : 29 August, 2018

Accepted : 29 November, 2018

Published : 31 December, 2018

(c) Authors retain copyright and grant the journal right of first publication with the work simultaneously licensed under Creative Commons Attribution License CC - BY 4.0 that allows others to share the work with an acknowledgment of the work's authorship and initial publication in this journal.

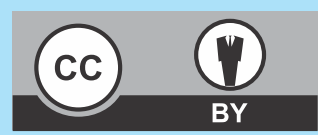

ORA 88

DOI: $\underline{10.3126 / \text { bjhs.v3i3.22173 }}$

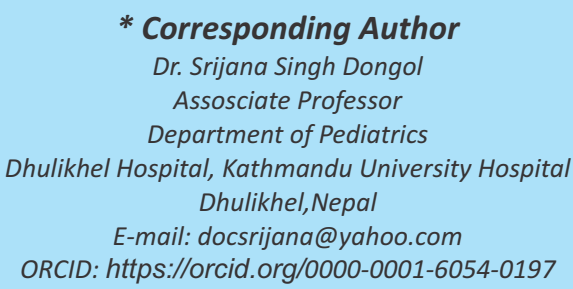

\section{Citation}

Dongol SS, Sradanandha S, Shrestha RPB, Bahadur R, Joshi A, Shrestha A, Pattern and Risk Factor Associated with Congenital Anomalies Among Young Infants Admitted in Dhulikhel Hospital. BJHS 2018;3(3)7:548-553.

\section{ABSTRACT}

\section{Introduction}

Birth defects are defined as structural and functional defects that develop during the organogenesis periods and present at birth or detected later in life. They are an important cause of morbidity and mortality in infants. The known causes of birth defects are mostly genetic effect modified by environmental factors which may be prevented.

\section{Objective}

The main objective of the study was to determine the association of certain risk factors with birth defects occurring in newborn and infant seeking care in Dhulikhel Hospital, Kavre, Nepal.

\section{Methodology}

This is a hospital based, cross sectional and comparative study involving 219 young infant below 2 months of age admitted in the Dhulikhel Hospital, Kathmandu University Hospital. We enrolled infants admitted at Neonatal intensive care unit, Neonatal ward, and neonates staying with mother in

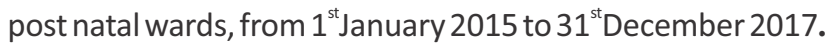

\section{Results}

Incidence of congenital malformations involvement of neonates in our hospital was $1.1 \%$ among the live births. The most frequent was cardiovascular systems $29(26.8 \%)$ followed by musculoskeletal system $17(15.7 \%)$ and face 15(13.8\%). Less than 4 in number of Antenatal visit $(p=0.017)$, not using folic acid during early pregnancy $(p<0.001)$ and low socioeconomic conditions $(p<0.001)$ were significantly associated with congenital malformations. Among all congenital anomalies complex congenital heart disease has poor outcome.

\section{Conclusion}

The most common congenital defects involved cardiovascular and musculoskeletal system. Lack of antenatal visit, lack of folic acid during periconceptional age and low socioeconomic conditions are the most common risk factors identified for congenital anomalies.

\section{KEYWORDS}

Congenital anomalies, risk factors, newborn 


\section{INTRODUCTION}

Congenital anomalies are defined as structural or functional abnormalities including metabolic disorders present at birth. It can be isolated abnormality or part of syndrome that continue to be an important cause of neonatal and infant morbidity and mortality. ${ }^{1,2}$ Fetal development is influenced by various genetic and environmental factors that leads to defective embryogenesis and intrinsic abnormalities resulting birth defect. ${ }^{3}$ In $60 \%$ cases, the certain causative factor are unexplained however in $40 \%$ of the cases there are recognized causative factors. ${ }^{4}$ The factors most commonly implicated are genetic conditions, environmental pollutions, teratogens, infections, drugs and uncontrolled medical disorders. The medical disorders are diabetes, hypertension, and eclampsia in antenatal periods. There are multi factorial inheritances responsible in most of anomalies. ${ }^{4}$

The frequency and specification of congenital anomalies differ from one country to another and from one place to another. In United States about 2-3\% birth prevalence of congenital anomalies has been reported. The birth prevalence of congenital anomalies in United Kingdom is $2 \%$ and in South Africa it is $1.49 \%$. In India it was found that, $2.5 \%$ of newborns were identified to have congenital anomalies at births. Congenital malformations are known to be the third commonest cause of perinatal mortality following infection and hypoxia. ${ }^{3}$

There has been a tremendous progress in the prenatal diagnosis of congenital malformation because of improvements in fetal ultrasound and prenatal genetic testing. This allows parents for the choice of terminating the pregnancy. Some studies have shown that prenatal folic acid and other multivitamins supplementations significantly reduce the birth prevalence of some congenital malformations. ${ }^{6-8}$ Early antenatal diagnosis of correctable defects gives the clinician an option for early referral of the mother to a center with pediatric surgical facilities for further plan and management in case of need.

There is no accurate quantification of congenital anomalies within certain populations and only few studies have been done regarding prevalence of congenital anomalies and its risk factors in country like Nepal. Therefore it is essential for estimating their burden and documenting the need for prevention and for evaluating the effects of preventive measures and treatment services. Even though congenital anomalies are a highly reported topic in scientific literature, very little information is available regarding the potential risk factors associated with these anomalies and their perinatal outcomes.

\section{OBJECTIVE}

To establish the prevalence and pattern of congenital anomalies and to identify association of the risk factor for congenital anomalies this study has been carried out.

\section{METHODOLOGY}

This is a hospital based, prospective, cross sectional and comparative study involving infants below 2 months of age admitted in the Dhulikhel Hospital, Kathmandu University Hospital. We enrolled 219 young infants admitted at Neonatal intensive care unit, Neonatal ward, and neonates staying with mother in perinatal ward from $1^{\text {st }}$ January 2015 to $31^{\text {st }}$ December 2017.The ethical approval was obtained from Institutional review committee of Kathmandu University School of Medical Science.

All 108 infants less than 2 months with congenital anomalies and 111 infants less than 2 months without congenital anomalies were recruited in this study. Young infants with congenital anomalies were recorded serially for 3 years. In this hospital based study, the number of cases is relatively small and slightly larger number of comparative group was maintained with 111 infants less than 2 months without congenital anomalies and by same birth years and APGAR score at 5 minutes more than 7 to ensure the necessary statistical power for detection of important risk factors. Diagnosis of congenital anomalies was based on clinical examination and relevant investigations. All infants had a thorough physical examination performed by the pediatrician. Appropriate investigations like $X$ - ray imaging (plain X-ray of chest and/or abdomen, barium meal enema), cranial and abdominal ultrasound, echocardiography and hematological and biochemical tests were done. X-ray films were interpreted by two independent radiologists. Ultrasonography was performed by the senior radiologist. Echocardiography was executed by a pediatrician who has done fellowship on pediatrics echocardiography. Due to lack of relevant equipment and qualified staffs, genetic and newborn metabolic assessments could not be performed.

After diagnosing congenital anomalies, informed consent was taken from parents and structured Proforma was filled. The patterns of congenital anomalies along with their system wise distribution were documented. The demographic patterns, risk factors associated with malformations and their outcomes were also documented. Christensen et al. defined multiple organ system involvement as live births with congenital anomalies that involved two or more organ systems. If they correspond with any identified syndrome, were categorized into the specific syndrome. Remaining unidentified anomalies were classified as others.

The parents were interviewed regarding detailed maternal and antenatal history including maternal and paternal age, periods of gestation, gravida, residential area, ethnicity, religion, socioeconomic status and number of antenatal care visit. Maternal age and paternal age were divided into three categories that are less than 19 years old, 19 to 35 years old and over 35 years depending upon the risk group. Gravida was divided into two categories that is primi being first time pregnant and multi being pregnant for two or more times. Religion was divided into four main categories that is Hinduism, Baddish, Islamic and Christian. Ethnicity were divided into 6 categories, Brahmin, Chetry, Newar, Tamang, Dalit and if none of above then into others. 
Socioeconomic conditions were divided into high class, average and low class depending on their residential area, educational and occupational status. The number of Antenatal visits was also divided into 2 categories according to World Health Organization (WHO), less than 4 visits and more than 4 visits.

History pertaining to risk factors for congenital anomalies like environmental factors alcohol consumption, smoking during pregnancy, exposure to radiation and drug use during pregnancy were recorded. The drug used during pregnancy for medical condition like epilepsy, diabetes and hypertension were considered in maternal medication. Clinical information such as history of Diabetes, Anemia, Hypothyroidism, TORCH (Toxoplasma, Rubella, CytoMegalo Virus and Herpes Simplex Virus) infection and any other infection during pregnancy were also noted. The periconceptional risk factors, family history of mother and father, first degree relatives and previous child with congenital anomalies were also recorded into the study. A marriage has been considered consanguineous when that is found to have occurred between a male and a female who are bloodrelated, e.g. between brother and sister, between first cousins. Detailed antenatal history was recorded including peri- conceptional use of folic acid and use of iron and calcium after first trimester. Pregnancy complications like preeclampsia, eclampsia, polyhydramnious, oligohydramnious, abruptio placenta and placenta previa were also recorded.

\section{Data analysis}

Data were entered and analyzed using SPSS, version 23. The prevalence of congenital anomalies was expressed per 1000 live births. The association between congenital anomalies and socio-demographics were assessed applying binomial logistic regression analysis for the study and reference group and chi square test was done between the study and reference group.

\section{RESULTS}

Within the study periods of 36 months 108 babies with congenital anomalies were identified. The age range was between first days of life up to 60 days of life with a median age of 3 days. Among 108 babies with congenital anomalies 98(90.7\%) babies were in born and 10 (9.25\%) babies were out born. In born babies were those who born within our hospital and out born babies were those who born outside our hospital including other hospital, health center, home delivery and ambulance delivery. The birth prevalence of congenital anomalies was 11.4 per 1000 live births.

Ninety one (84.2\%) babies had a single malformation while $17(15.7 \%)$ babies had multiple malformations. The most frequent site of malformations involved cardiovascular systems $29(26.8 \%)$ followed by musculoskeletal system $17(15.7 \%)$ and face 15 (13.8\%). Distribution of congenital anomalies in the study group is shown in Figure 1 . The specific congenital anomalies, found within different system in the present study is shown in table 1.

Among the socio demographic studies there was no significant difference in maternal age, paternal age, residence, week of gestation, religion and ethnicity. Number of Antenatal care visit was significantly associated with congenital anomalies (OR=2.6; 95\% $\mathrm{Cl}=1.8-5.8 ; \mathrm{p}=0.017)$ (Table 2).

Maternal TORCHinfections, smoking during pregnancy and alcohol intake during pregnancy were more common in the study group but these differences were not significant. Failure in use of folic acid during early phase of pregnancy has a strong association with congenital anomalies with $p$ value of 0.000 (Table 3).

Male babies $(p=0.002)$ and Low socioeconomic condition $(p=0.000)$ were also significantly associated with congenital anomalies (Table 4).

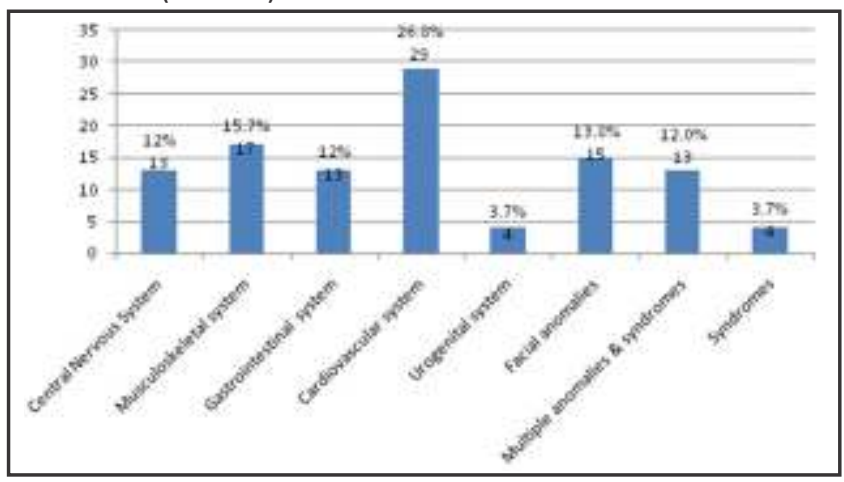

Figure 1: Distribution of congenital anomalies

Table 1: Specific congenital anomalies in different system Specific anomalies Number (\%)

CNS anomalies

$13(100)$

Hydrocephalus

5(38.4)

Hydrocephalus with Dandy Walker cyst

2(15.3)

Meningomyelocele with hydrocephalus

Arnold Chiari malformation

Hydrocephalus with Aqueductal stenosis

with Spinabifida

Vein of Galen Malformation

Hydrocephalus with Spina bifida with VSD

Musculo skeletal system anomalies

17 (100)

Club foot

$5(29.4)$

Polydactyly

$5(29.4)$

Hernias (Inguinal and Umbilical)

$3(17.64)$

Syndactyly

2(11.76)

Choanal atresia

Ankyloglossia

Gastrointestinal system

$13(100)$

Imperforated anus

$3(23)$

Pyloric stenosis

Diaphragmatic hernia

Hirschsprungdisease

$1(7.6)$

Biliary atresia

Illeal atresia

Gastroschisis 


\section{Cardiovascular system}

$29(100)$

ASD

VSD

VSD with ASD

ASD with PDA

ASD with pulmonary hypertension

Aortic stenosis

Transposition of great arteries (TGA)

Complex congenital heart disea

\section{Urogenital system}

4(100)

Hypospadias

2 (50)

$1(25)$

1 (25)

Multidysplastic kidney

\section{Facial}

$13(100)$

2 (15.38)

1 (7.69)

1 (7.69)

1 (7.69)

opacity with CHD

Polycystic kidney disease with

ventriculomegaly with polydactyly

1 (7.69)

1 (7.69)

1 (7.69)

Meningomyelocele with midline cleft palate

Holoprosencephaly with ASD with cleft

palate with club foot

1 (7.69)

$2(15.38)$

Hydrocephalus with VSD

Cleft lip and palate with polydactyly with

Ambiguous genitalia

\section{Syndromes}

4(100)

Down Syndrome

1 (25)

Pierre Robin Syndrome

Table 2: Logistic regression analysis of sociodemographic between study and reference group.

$\begin{array}{lll}\text { Variables } & \begin{array}{l}\text { Study } \\ \text { group group }\end{array} & \end{array}$

\section{Maternal age}

$\begin{array}{llll}<19 \text { years } & 13 & 13 & - \\ 19-35 \text { years } & 82 & 96 & - \\ >35 \text { years } & 13 & 2 & -\end{array}$

\section{No. of ANC visit}

$\begin{array}{lllll}<4 & 65 & 38 & 2.64(1.88-5.86) & 0.017 \\ >4 & 43 & 73 & & \end{array}$

Table 3: Logistic regression analysis of risk factor between study and reference group.

$\begin{array}{lccccc}\text { Variables } & \begin{array}{l}\text { Study } \\ \text { group }\end{array} & \begin{array}{l}\text { Reference } \\ \text { group }\end{array} & \text { OR }(95 \% \mathrm{CI}) & \text { P value } \\ \text { TORCH positive } & 7 & 0 & 0.00(0.00-0.00) & 0.99 \\ \text { Maternal Smoking } & 25 & 2 & 1.35(0.04-1.11) & 0.78 \\ \text { Maternal alcohol } & 36 & 6 & 0.21(0.04-1.11) & 0.06 \\ \text { Folic acid intake } & 11 & 89 & 31.91(13.67-74.45)<0.001\end{array}$

Table 4: Chi-sauare test analysis of sociodemographics between study and reference group

$\begin{array}{lccc}\text { Variables } & \begin{array}{l}\text { Study } \\ \text { group }\end{array} & \begin{array}{l}\text { Reference } \\ \text { group }\end{array} & \text { P value } \\ \text { Sex } & 71 & 48 & 0.002 \\ \text { Male } & 37 & 63 & \\ \text { Female } & 4 & 4 & \\ \text { Socioeconomic Condition } & & \\ \text { High class } & 47 & 94 & <0.001 \\ \text { Average class } & 57 & 13 & \\ \text { Low class } & 47 & & \end{array}$

\section{DISCUSSION}

The joint World Health Organization (WHO) and March of Dimes (MOD) meeting reported that $7 \%$ of all neonatal mortality and 3.3 million under five death were due to congenital anomalies. ${ }^{9}$ Several studies have been done to determine its prevalence. However, since most of the studies done were limited to a single institute or region and not nation-wide, birth defect prevalence varied widely from $0.5 \%$ to $6.8 \% .{ }^{10,11}$ In our study incidence of congenital malformations in neonates was $1.1 \%$ among the live births which was significantly higher than previous two studies done in maternity hospital $(0.36 \%)$ and Western regional hospital (0.42\%) in Nepal. ${ }^{12,13}$ In England and United State, the prevalence is $2 \%$ and $2-3 \%$ respectively. ${ }^{5,14}$ The prevalence of congenital malformation in our study is also comparable to another study done in United Arab Emirates (1\%) and china (1.1\%). ${ }^{14}$

The prevalence by type of anomaly showed known global trends, with congenital heart defects being the most prevalent type of birth defect. The prevalence of congenital heart defect was 3.3 per 1000 live birth that is nearly threefold lower than the estimated prevalence of 9.3 per 1000 live births for Asia. ${ }^{15}$ Another multiethnic birth cohort study done in Brandford UK, also reported congenital heart disease as the most common anomaly in newborn in UK. ${ }^{16}$ In contrast to our study, other studies done in developing countries like in India $^{17}$ and Pakistan ${ }^{18}$ demonstrated highest frequency of CNS anomalies and lowest frequency of congenital heart disease. The variation in the frequencies could be due to genetic background, geographical area, socioeconomic and nutritional status along with folic acid intake. This may be due to routine performance of echocardiography in all babies admitted in NICU and all suspected congenital heart 
disease admitted in our center which leads to the increased detection of CHD in our study. During the study periods there was a predominance in infants with cardiovascular system, followed by musculoskeletal system and facial malformation, resembling those found in other national studies and in first World countries like the United States and Europe. ${ }^{19,20}$ Another study done in Nepal has also shown musculoskeletal system as second most common system involved in congenital malformation. ${ }^{12}$ The predominance of musculoskeletal and facial malformation could be related to easiness for diagnosis and its visibility during routine physical head to toe examination. The prevalence of CNS malformation is less in comparison to previous studies. ${ }^{17,18}$ It may be due to early detection and termination during anomaly scan in early pregnancy.

Multiple logistic regression analysis to determine the variables with the greatest association with congenital malformation showed results that have been recognized in the scientific literature. The current sample did not show any association between congenital anomalies with maternal age and paternal age. Similar result was also shown in the studies done in Chile by Pardoetal ${ }^{21}$ and in Brazil by Costa Cet al ${ }^{22}$.

Antenatal visits are an important aspect of prenatal care. These visits aim to ensuring a normal pregnancy with the delivery of a healthy baby from a healthy mother. Inadequate ANC visits ( $<4$ ) have previously been associated with the occurrence of congenital anomalies. ${ }^{22,23}$

A significant association between congenital anomalies and the lack of periconceptional use of folic acid ( $p=\leq 0.001$ ) was found in this study. Folic acid is necessary for the growth and smooth functioning of human cells, as it is crucial for the biosynthesis and methylation of deoxyribonucleic acid (DNA) and ribonucleic acid (RNA). ${ }^{24}$ This is important for cell division, differentiation and regulation of gene expression, especially at the time of rapid cell division that is during embryogenesis. ${ }^{24}$ The association between a low usage of folic acid during pregnancy and the occurrence of congenital anomalies has also been reported in other studies. ${ }^{23,25,26}$

Maternal cigarettes smoking and alcohol consumption have previously been reported as risk factors for the occurrence of congenital anomalies including orofacial clefts and congenital heart disease. ${ }^{27,28}$ The current study did not show a significant difference in smoking or alcohol consumption during pregnancy when comparing mothers of newborns with or without a diagnosis of congenital malformation. This may be due to awareness programs and cultural norms. Similar to our study, other studies done in Brazil and Tanzania also showed insignificant association between maternal cigarette smoking and alcohol consumption for the occurrence of congenital anomalies. ${ }^{16,22,23}$

Male babies were significantly high with congenital anomalies than females in the present study. This finding is consistent with that of Shaw et al, which observed an increased risk for congenital anomalies in male babies of various system including urogenital, cardiovascular and gastrointestinal system. ${ }^{29}$ Male preponderance was similar in other studies as well. ${ }^{30,31}$

Socioeconomic status for most was low class. This could be one of the reasons for a high percentage of affected patients in our setting as socioeconomic status in an important risk factor for birth defect. ${ }^{32-34}$ Some hypothesis can be raised, including the possibility that mother may having inadequate nutrition, less ANC visit and lack of awareness about folic acid and risk of congenital anomalies .

Among all congenital anomalies mortality was high among those with complex congenital heart disease due to unavailability of advance neonatal cardiac surgical facility in our country.

Congenital malformation has gained increasing importance due to both its morbidity and mortality. There are no well accepted preventive measures for it. Increasing awareness about maternal care during pregnancy, education programs on risk factor for congenital malformation and preconception use of folic acid needs to be highlighted to decrease the incidence of congenital anomalies and their co morbidities.

\section{LIMITATIONS}

There are several limitations in our study. As this is a hospital-based study, its result is unlikely to represent nationally. Chromosomal abnormalities and metabolic disease could not be diagnosed and confirmed because of lack of availability of Karyotyping and metabolic screening test. Since our study was conducted in just one tertiary care center, many cases could not be included. This has led to a low percentage of this relatively common birth defect in our sample.

\section{CONCLUSION}

The prevalence of congenital malformation in this study was 11.4 per 1000 total lives births. Less than 4 antenatal visits, lack of intake of folic acid and low socioeconomic condition were three most common risk factors as determined from our study. Regular antenatal visits to emphasize the intake of folic acid in early pregnancy and prenatal diagnosis are recommended for prevention, early intervention and even planned termination when needed.

\section{Funding}

This study did not receive funding.

\section{CONFLICTS OF INTEREST}

We declare that we have no conflicts of interest.

\section{ACKNOWLEDGMENTS}

We thank the families who took part in this study. We would also like to thank all nursing staff of Pediatrics and pediatricians for their help in recruiting them. 


\section{REFERENCES}

1. Rosano A, Botto LD, Botting B, Mastroiacovo P. Infant mortality and congenital anomalies from 1950 to 1994: an international perspective. Journal of epidemiology and community health 2000; 54:660-6.DOI:10.1136/PMID:10942444

2. Agha MM, Williams JI, Marrett LD, To T, Zipursky A, DoddsL. Determinants of survival in children with congenital abnormalities: a long term population- based cohort study. Birth defects research Part A, Clinical and molecular teratology 2006; 76:46-54.DOI: 10.1002

3. Slavotinev A. Dysmorphology. In: Kliegman,Stanton, St, editors. Nelson Textbook of Pediatrics. Vol 1.1 $1^{\text {st }}$ South Asia Edithion. Elsevier; 899-909.

4. Brohi R A, Brohi R S, Khaskhel S. Pattern and frequency of craniospinal anomalies. Journal of Surgery Pakistan.2008; 13:67-70.

5. Bari A. Birth prevalence and distribution of congenital anomalies in a university hospital. Perinatol Dergisi 2005; 13:86-90.

6. Creizel AE. The primary prevention of birth defect: multivitamins or folic acid. Int J Med Sci 2004; 1:50-61.PMID:15912190.

7. Batto LC, Olney RS, Erickson JD. Vitamin supplements and the risk of congenital anomalies other than neural tube defect. Am J Med Genet CSemen Med Genet 2004; 125C:12-21.DOI:10.1002

8. Czeizel AE. Prevention of congenital abnormalities by periconceptional multivitamin supplementation. BMJ 1993; 306:1645-8.DOI:10.1017

9. World health organization. Management of birth defect and hemoglobin disorders: report of a joining WHO-March of dimes meeting. Geneva, Switzerland, Geneva: WHO; 2006.

10. Kim SJ, Kim SP. Clinical study of the lethal anomalies by antenatal ultrasonograpy. Korean J Obster Gyaecol 1998; 41:1459-64.

11. McIntosh R, Merritt KK, Richrd MR, Samuels Mh, Bellows MT. The incidence of congenital malformation: a study of 5,964 pregnancies. Pediatrics 1954; 14:505-22.

12. Malla BK. One year review study of congenital anatomical malformation at birth in Maternity Hospital, Prasuigriha, Thapathali. Kathmandu Univ Med J (KUMJ) 2007; 5:557-60

13. Sharma I, Rijal BT, Thapa SB, Poudell. Congenital anatomical malformation at birth in Western Regional Hospital, Pokhara, Nepal. Journal of Universal College of Medical Sciences 2013; 1(4):3740.DOI:10.3216.

14. Biri A, Onan A, Korucuglu U, Tiras B. Birth prevalence and distribution of congenital anomalies in a university hospital. Perinatol Dergisi. 2005; 13:86-9.

15. Van der Linde $D$, Konings EE, SlagerMA, Witsenburg M, Helbing WA, Takkenberg JJ et al. Birth Prevalence of congenital heart disease worldwide: a systemic review and meta- analysis. J Am CollCardiol. 2011; 59(21):2241-7.DOI:10.1016

16. Sheridan E, Wright J, Small N, Corry C P, OddieS, Whibley C et al. Risk factors for congenital anomaly in multiethnic birth cohort: an analysis of the Born in Bradford study. Lancet 2013; 383:1350-59.DOI:10.1016

17. Tella S, Kattekola RP, Tiruvtturu KM, Buragadda S, Madireddy LND, Ramaiah A, Akka J. Risk factor for congenital anomalies in high risk pregnant women: Alarge study from South India. The Egyptian Journal of Medical Human Genetics. 2017; 18:79-85.DOI:10.1016
18. Fauzia B, Raffia S, Irfan P. Pattern and outcome of congenital anomalies and maternal risk factor association. Biomedica. 2013; 29:234-240.DOI:10.1590

19. Pinto Co, Nascimento LF. Prevalence study of birth defects in Vale so Paraiba, Sao Pauli, Brazil. Rev Paul Pediatr.2007; 25:233-9.

20. Ramos JI, Laurindo VM, Vaz FA, Araujo J, Zuccolotto M, Corradini HB et al. Congenital malformation: prospective study of two years in three maternity hospitals.Pediatria 1981;3:20-8.

21. Pardo RA, Nazer J, Cifuentes L. Prevalencia al nacimiento de malformacionescongenitas y de menon peso de nacimientioenhijos de madresadolesenetes. Rev Med Chile 2003; 131:1165-72.

22. C M S Costa, S G N Gama, MD C Leal. Congenital malformation in Rio de Janeiro, Brazil: prevalence and associated factors.Cad. SaudePublica, Riao de Janeiro. 2006; 22(11)2423-2431.PMID:1709119

23. Mashuda F, Zuechner A, Chalya L P, Kidenya R B, Manyama M. Pattern and factors associated with congenital anomalies among young infants admitted at Bugando medical center, Mwanza, Tanzania. BMC research Notes 2014;7:195.DOI:10.1186/PMID:24679067

24. Wisniewska K, WysockiJ. The importance of folic acid in the primary prevention of congenital malformations. Arch perinat Med 2008; 14(4):258-261.

25. Verity $\mathrm{C}$, Firth $\mathrm{H}$, Constant $\mathrm{C}$. Congenital abnormalities of the central nervous system. Neurol Neurosurg Psychiatry 2003:74:1318.DOI:10.1136

26. GranadoS. Congenital malformations in Rio de Janeiro, Brazil: prevalence and associated factors. Cad Saudepublica 2006; 22(11):2423-2431.DOI:10.1590

27. Hackshaw A, Rodeck C, Boniface S. Maternal smoking in pregnancy and birth defect. Hum Repro Update 2011; 17(5):589604.DOI:10.1093/PMID:21747128

28. MehrabiKushki BZ. The effect of consanguineous marriage on congenital malformation. J Res Med Sci 2005; 10(5):298-301.

29. Shaw GM, Carmichael SL, Kaidarova Z, Harris JA. Differential risks of males and females for congenital malformation among 2.5 million Calfornia births, 1989-1997. Birth Defects Res AClinMolTeratol 2003; 67(12):953-958.DOI:10.1002/PMID:14745913

30. Mohanty C, Mishra OP, Das BK, Bhatiaa BD, Singh G. Congenital malformation in newborn of consecutive births. J Anta Soc India.1989; 56:101-11.

31. Chaturvedi P, Banerjee KS. Spectrum of congenital malformations in the newborns from rural Maharastra. Indian J Pediatr. 1989; 56:501-7.

32. Vrijheil M, Dolk H, Stone D, Abramsky L, Alberman E, Scott J. Socioeconomic inequalities in risk of congenital anomaly. Arch Dis Child 2000; 82(5):349-352.DOI:10.1136/PMID:10799420

33. Varela MMMS, Nohr EA, Llopis-Gonzalez A, Andersen AMN, Olsen J. Sociooccupational status and congenital anomalies. Eup J Public Health 2009; 19(2):161-167.DOI:10.1093/PMID:19221022

34. Raza Z M, Shikh A, Ahmed SS, Ali A, Ali MS, Naqvi MS. Risk factor associated with birth defect at a tertiary care center in Pakistan. Italian Journal of Pediatrics 2012; 38:68-73.DOI:10.1186/ PMID: 232117204 